\title{
Bioprospecting Certain Freshwater-derived Fungi for Phenolic Compounds with Special Emphasis on Antimicrobial and Larvicidal Activity of Methyl Gallate and $p$-coumaric Acid
}

\author{
Marwa T. A. Abdel-Wareth ${ }^{1 *}$, Mosad A. Ghareeb ${ }^{2}$ \\ ${ }^{1}$ Environmental Research and Medical Malacology Department, Theodor Bilharz \\ Research Institute, Giza, Egypt. \\ ${ }^{2}$ Medicinal Chemistry, Biochemistry and Molecular Biology Department, Theodor \\ Bilharz Research Institute, Giza, Egypt.
}

\begin{abstract}
$\mathbf{F}$ UNGI naturally produce secondary metabolites which have been investigated as biologically active compounds. This work aimed at exploring phenolic compounds profile of three freshwater derived fungi, and investigating the antimicrobial and larvicidal activity of methyl gallate and $p$-coumaric acid as two major compounds detected. Reverse phase high performance liquid chromatography coupled with diode array detector (RP-HPLC-DAD) revealed the presence of 22 phenolic compounds in the filtrate extracts of Penicillium implicatum, Aspergillus niveus and Aspergillus petrakii, although they varied in their concentrations from one species to another, methyl gallate was one of the major compounds in Penicillium implicatum and Aspergillus niveus filtrates, and the compound of the highest concentration in Aspergillus petrakii filtrate. While $p$-coumaric acid was the major compound in Aspergillus niveus filtrate. Methyl gallate was effective on Pseudomonas aeruginosa, Escherichia coli and Staphylococcus aureus sub sp. aureus (MRSA), while p-coumaric acid was only effective on Bacillus cereus. Regarding larvicidal activity, $p$-coumaric acid was more effective on Schistosoma mansoni cercariae than methyl gallate. The investigated fungi comprise a rich source of phenolic compounds, and methyl gallate and $p$-coumaric acid represent promising antibacterial and larvicidal agents.
\end{abstract}

Keywords: Penicillium, Aspergillus, RP-HPLC, methyl gallate, $p$-coumaric acid, antimicrobial effect, Larvicidal activity

\section{Introduction}

Naturally occurring secondary metabolites are considered leading compounds that can be used for new drug discovery [1]. At present, the search for new producers of biologically active compounds is diligently underway among fungi from unusual or specialized ecological niches, because the synthesis of new secondary metabolites is crucial for these fungi to survive and adapt to their environments [2-4]. Additionally, freshwater-derived fungi are being accepted as a potentially important source of novel compounds that might prove suitable for specific medicinal or agrochemical applications [5]. Many novel bioactive compounds have been reported from freshwater-derived fungi; Stachybotrys sp. [6], Kirschsteiniothelia sp. [7], Dendrospora tenella [8], Massarina tunicata [9], Annulatascus triseptatus [10], Ophioceras venezuelense [11], Decaisnella hyridioides [12] and Helicodendron giganteum [13]. On the other hand, the increasing occurrence of highly resistant pathogenic microorganisms against antibiotics is a great challenge. Thus, there is a crucial demand for the isolation and identification of new therapeutic agents to overcome infectious diseases [14]. Schistosomes larval stages; miracidia and cercariae are key organisms in incidence of schistosomiasis, so searching for compounds from biological origin to kill these larvae is encouraged.

The reversed phase-high performance liquid chromatography coupled with diode array detector (RP-HPLC-DAD) is a unique technique widely used for the separation and quantification of polyphenolic compounds either in plants, marine organisms or fungal extracts [15]. Therefore, the aims of the current study were to identify 
the phenolic compounds profile of filtrates from three fungal species; Penicillium implicatum, Aspergillus niveus and Aspergillus petrakii using RP-HPLC-DAD technique, and to determine the presence of biologically active compounds by evaluating their in vitro antimicrobial and larvicidal activity.

\section{Materials and Methods}

\section{Chemicals}

Sabouraud dextrose agar media, MuellerHinton agar medium, glucose, acetic acid, acetonitrile, toluene, ethyl acetate, formic acid and DMSO were analytical grade. Standard gallic acid, pyrogallol, 4-amino-benzoic acid, protocatechuic acid, catechin, chlorogenic acid, methyl gallate, epicatechin, caffeic acid, vanillic acid, $p$-coumaric acid, ferulic acid, iso-ferulic acid, reversetrol, ellagic acid, $e$-vanillic acid, $\alpha$-coumaric acid, benzoic acid, 3,4,5- methoxy cinnamic acid, coumarin, salicylic acid and cinnamic acid were purchased from SigmaAldrich Co., polymyxin, ampicillin, kanamycin and nystatin antibiotics were provided by faculty of Agriculture, Cairo University.

\section{Preparation of fungal filtrates}

Three fungal species; namely Penicillium implicatum, Aspergillus niveus and Aspergillus petrakii were previously isolated from watercourses at Ismailia, Giza and Gharbeya governorates, respectively [16]. They were identified microscopically using universal manuals $[17,18]$, maintained by continuous sub culturing on Sabouraud dextrose agar at constant intervals, and the slants then kept refrigerated. Fungal cultures were prepared by inoculating conical flasks (250 ml capacity) containing 50 $\mathrm{ml}$ of potato dextrose broth medium with fungal discs (5 mm diameter) which were cut from 7 days old cultures [19]. The inoculated flasks were incubated on a rotary shaker $(150 \mathrm{rpm})$ at $28^{\circ} \mathrm{C}$ for 10 days. The mycelia then were separated by filtration, using a membrane filter. The resultant filtrates were used for analysis.

\section{Separation and quantification of phenolic compounds}

Separation and determination of phenolic compounds were performed by reverse phase HPLC (RP-HPLC)/diode array detection (DAD) (Hewlett Packard 1050) using a column Alltima C18, 5mm (150 mm_4.6 mm id) with a guard column Alltima C18, $\overline{5} \mathrm{~mm}$ (Alltech). The solvent Egypt.J.Chem. 61, No.5 (2018) system used was a gradient of $\mathrm{A}\left(\mathrm{CH}_{3} \mathrm{COOH} 2.5 \%\right.$ $\mathrm{v} / \mathrm{v}), \mathrm{B}\left(\mathrm{CH}_{3} \mathrm{COOH} 8 \% \mathrm{v} / \mathrm{v}\right)$ and $\mathrm{C}$ (acetonitrile). The best separation was obtained with the following gradient: at $0 \mathrm{~min}, 5 \% \mathrm{~B}$; at $20 \mathrm{~min}, 10 \%$ $\mathrm{B}$; at $50 \mathrm{~min}, 30 \% \mathrm{~B}$; at $55 \mathrm{~min}, 50 \% \mathrm{~B}$; at $60 \mathrm{~min}$, $100 \% \mathrm{~B}$; at $100 \mathrm{~min}, 50 \% \mathrm{~B}$ and $50 \% \mathrm{C}$; at 110 min, $100 \%$ C until $120 \mathrm{~min}$. The solvent flow rate was $1 \mathrm{ml} / \mathrm{min}$, and the separation was performed at $35^{\circ} \mathrm{C}$. The volume injected was $10 \mathrm{ml}$. Phenolic compounds were assayed by external standard calibration at $280 \mathrm{~nm}$ and expressed in $\mu \mathrm{g} / 100 \mathrm{ml}$. All values were the mean of two injections [20].

Chromatographic isolation of methyl gallate and p-coumaric acid from fungal filtrates extracts

As the largest peak areas of methyl gallate and $p$-coumaric acid were noticed in the filtrates of Penicillium implicatum and Aspergillus niveus, respectively, preparative thin layer chromatography (PTLC) was used to separate methyl gallate and $p$-coumaric acid from these species. TLC plates $(20 \times 20 \mathrm{~cm}$ Merck aluminum sheet, silica gel 60, layer thickness $0.2 \mathrm{~mm}$ ) were used. Each fungal filtrate extract was spotted at the start of the silica gel plates, and allowed to dry, then eluted using toluene: ethyl acetate: $90 \%$ formic acid (TEF) (5:4:1, v/v/v) in a solvent saturated atmosphere, then allowed to air dry. TLC plates were examined under UV light (365 $\mathrm{nm}$ ) to determine the spots which had the same $R_{f}$ values of authentic methyl gallate and $p$-coumaric acid $[21,22]$. Then, the in vitro antimicrobial and larvicidal activity of the purified compounds were evaluated.

\section{Antimicrobial activity}

The antimicrobial activity was determined using disc diffusion assay [23]. In vitro antibacterial activity was carried out against Escherichia coli and Pseudomonas aeruginosa (Gram negative bacteria), Bacillus cereus and Staphylococcus aureus sub sp. aureus (MRSA) (Gram positive bacteria), using Mueller-Hinton agar medium. Antifungal activity was carried out against Aspergillus niger and Candida albicans using Sabouraud dextrose agar medium. Kanamycin $(30 \mu \mathrm{g})$, Ampicillin $(10 \mu \mathrm{g})$, Polymyxin (130 units) and Nystatin (100 units) were used as positive reference standards for Gram positive, Escherichia coli, Pseudomonas aeruginosa and antifungal activity, respectively. DMSO was used as solvent and negative control. Briefly, $20 \mathrm{ml}$ of sterilized media was poured onto the sterilized Petri-dishes and allowed to 
solidify. $0.5 \mathrm{ml}$ of each microbial suspension was poured on the surface of the solidified media, and evenly distributed using a sterile swab. Discs saturated with $15 \mu$ l of the purified compound (with a concentration equals $10 \%$ $\mathrm{v} / \mathrm{v}$ ) and antibiotics solutions were placed in triplicates on the surface of the media. The plates were incubated at $30^{\circ} \mathrm{C}$ for Bacillus cereus, $37^{\circ} \mathrm{C}$ for other bacterial species, and $25^{\circ} \mathrm{C}$ for tested fungi; all plates were incubated and investigated after 24-48 hrs. Zones of inhibition were measured in mm scale.

\section{Larvicidal effect}

To investigate miracidicidal effect, Schistosoma mansoni ova were allowed to hatch in dechlorinated tap water. $250 \mu \mathrm{m}$ of water containing about 50-100 freshly hatched miracidia was mixed with $250 \mu \mathrm{m}$ of each concentration tested $(25 \mathrm{mg} / \mathrm{ml}, 50 \mathrm{mg} / \mathrm{ml}$ and $100 \mathrm{mg} / \mathrm{ml})$ in a divided Petri dish. $250 \mu \mathrm{m}$ of dechlorinated water containing about 50-100 miracidia was kept as control. After 15, 30, 45 and $60 \mathrm{~min}$, the miracidia were observed under a dissecting microscope for alterations in their motility. Motionless miracidia were considered dead and the mortality rates were recorded. For cercariae, $250 \mu \mathrm{m}$ of water containing about 50-100 freshly shed S. mansoni cercariae were mixed with $250 \mu \mathrm{m}$ of the tested concentrations as in the miracidicidal test. Motionless cercariae were considered dead and their mortality was recorded [24]. Schistosoma mansoni ova and cercariae were kindly provided by Schistosome Biological Supply Center (SBSC) at Theodor Bilharz Research Institute (TBRI).

\section{Results and Discussion}

RP-HPLC/DAD analysis of Penicillium implicatum filtrate extract showed the presence of two major compounds namely; $e$-vanillic acid $(2.14 \%)$ and methyl gallate $(1.12 \%)$, and other minor compounds like 3,4,5-methoxy cinnamic acid $(0.78 \%)$ and $p$-coumaric acid $(0.75 \%)$ (Table 1 and Fig. 1). Regarding Aspergillus niveus filtrate extract, the analysis revealed the presence of one major compound, namely; $p$-coumaric acid $(1.35 \%)$, beside methyl gallate $(0.98 \%)$, protocatechuic acid $(0.84 \%)$, 4-amino-benzoic acid $(0.66 \%)$ and chlorogenic acid $(0.63 \%)$ (Table 2 and Fig. 2). While, for Aspergillus petrakii extract, this analysis showed the presence of methyl gallate $(0.73 \%)$, vanillic acid $(0.70 \%)$, gallic acid $(0.57 \%)$ and $e$-vanillic acid (0.50\%) (Table 3 and Fig. 3). From the obtained results, we can conclude that there are mutual compounds in the three tested species but in different concentrations, and this indicated the chemical similarity of these fungal species. To the best of our knowledge, there are very limited data concerning the RP-HPLC-DAD analysis of the three investigated fungal species. Reviewing the literature revealed that some bioactive phenolic secondary metabolites were isolated and identified in different Penicillium species; viz., (3,1' -didehydro3 [z2"(3"',3"',-dimethyl-prop-2-enyl)-3"indolyl methylene]-6-methyl pipera-zine-2,5-dione) [25], 7-methoxy-2,2-dimethyl-4-octa-4', 6'-dienyl-2 $H$ napthalene-1-one [26], citreorosein, emodin, janthinone, citrinin, citrinin $\mathrm{H} 1$ and dicitrinol [27]. On the other hand, sesquiterpenes, alkaloids and quinines have been previously reported in some Aspergillus species [28,29].

Methyl gallate is a derivative of gallic acid. It was previously isolated from plants showing medicinal properties, e.g. Toona sureni [30] and Spondias pinnata [31]. Also, it was identified and isolated from the filtrate of the fungus Penicillium janthinellum [16]. Many studies showed its multiple biological activities as antioxidant, anti proliferative and anticancer agent [31-33]. The current study showed that methyl gallate was effective on both tested Gram negative bacteria; Pseudomonas aeruginosa and Escherichia coli as the diameters of inhibition zones were 9 and $13 \mathrm{~mm}$ as compared to 10 and $15 \mathrm{~mm}$ for polymyxin and ampicillin, respectively. Additionally, it was effective against Staphylococcus aureus sub sp. aureus (MRSA) as a Gram positive bacterium with an $8 \mathrm{~mm}$ inhibition zone (Table 4 and Fig. 4). On the other hand, methyl gallate did not show antimicrobial effect on each of Bacillius cereus, Aspergillus niger and Candida albicans. These results agree with the findings reported by Choi et al., they mentioned that methyl gallate, as a major component of Galla rhois, exhibited strong antimicrobial activity against $E$. coli [34]. Moreover, Ekaprasada et al. showed that $10 \mathrm{mg} / 1$ of methyl gallate isolated from the leaves of Toona sureni showed antibacterial activities against each of Bacillus subtilis, Staphylococcus aureus and $E$. coli with inhibition zones equal 8,10 and $8 \mathrm{~mm}$, respectively [30]. Phenolic compounds are thought to inhibit microbial enzymes possibly through reaction with sulfhydryl groups (the oxidized phenols) or through nonspecific interactions with the proteins [35]. 
TABLE 1. The phenolic compounds identified in Penicillium implicatum filtrate by reverse phase HPLC with diode-array detection.

\begin{tabular}{|c|c|c|c|c|}
\hline Peak No. & R.T. (min) & Area \% & Identified compound & $\mu \mathrm{g} / 100 \mathrm{ml}$ \\
\hline 1 & 7.26 & 0.32 & Gallic acid & 53.74 \\
\hline 2 & 7.37 & 0.12 & Pyrogallol & 833.58 \\
\hline 3 & 7.93 & 0.30 & 4-Amino-benzoic acid & 18.66 \\
\hline 4 & 8.65 & 0.18 & Protocatechuic acid & 80.70 \\
\hline 5 & 8.69 & 0.10 & Catechin & 56.69 \\
\hline 6 & 9.21 & 0.23 & Chlorogenic acid & 57.86 \\
\hline 7 & 9.53 & 1.12 & Methyl gallate & 285.00 \\
\hline 8 & 9.69 & 0.10 & Epicatechin & 23.83 \\
\hline 9 & 10.24 & 0.25 & Caffeic acid & 19.19 \\
\hline 10 & 10.35 & 0.17 & Vanillic acid & 63.48 \\
\hline 11 & 11.75 & 0.75 & $p$-Coumaric acid & 89.24 \\
\hline 12 & 11.86 & 0.13 & Ferulic acid & 19.90 \\
\hline 13 & 12.08 & 0.40 & Iso-ferulic acid & 68.51 \\
\hline 14 & 12.63 & 0.14 & Reversetrol & 7.65 \\
\hline 15 & 13.03 & 0.35 & Ellagic acid & 932.51 \\
\hline 16 & 13.10 & 2.14 & $e$-vanillic acid & 8021.09 \\
\hline 17 & 13.28 & 0.26 & $\alpha$-Coumaric acid & 42.48 \\
\hline 18 & 13.43 & 0.30 & Benzoic acid & 516.93 \\
\hline 19 & 13.92 & 0.78 & 3,4,5- methoxy cinnamic acid & 11.73 \\
\hline 20 & 14.04 & 0.19 & Coumarin & 23.41 \\
\hline 21 & 14.39 & 0.19 & Salicylic acid & 131.51 \\
\hline 22 & 15.15 & 0.20 & Cinnamic acid & 12.08 \\
\hline \multicolumn{5}{|c|}{ Total } \\
\hline
\end{tabular}

TABLE 2. The phenolic compounds identified in Aspergillus niveus filtrate by reverse phase HPLC with diodearray detection.

\begin{tabular}{|c|c|c|c|c|}
\hline Peak No. & R.T. (min) & Area \% & Identified compound & $\mu \mathrm{g} / 100 \mathrm{ml}$ \\
\hline 1 & 7.29 & 0.13 & Gallic acid & 12.04 \\
\hline 2 & 7.34 & 0.27 & Pyrogallol & 970.06 \\
\hline 3 & 7.93 & 0.66 & 4-Amino-benzoic acid & 22.21 \\
\hline 4 & 8.64 & 0.84 & Protocatechuic acid & 202.17 \\
\hline 5 & 8.68 & 0.20 & Catechin & 56.79 \\
\hline 6 & 9.24 & 0.63 & Chlorogenic acid & 86.84 \\
\hline 7 & 9.55 & 0.98 & Methyl gallate & 135.72 \\
\hline 8 & 9.72 & 0.28 & Epicatechin & 34.73 \\
\hline 9 & 10.27 & 0.58 & Caffeic acid & 24.26 \\
\hline 10 & 10.38 & 0.54 & Vanillic acid & 108.31 \\
\hline 11 & 10.64 & 1.35 & $p$-Coumaric acid & 87.07 \\
\hline 12 & 10.88 & 0.32 & Ferulic acid & 26.90 \\
\hline 13 & 12.20 & 0.58 & Iso-ferulic acid & 54.33 \\
\hline 14 & 12.61 & 0.11 & Reversetrol & 3.08 \\
\hline 15 & 13.01 & 0.03 & Ellagic acid & 57.26 \\
\hline 16 & 13.04 & 0.06 & $e$-vanillic acid & 124.44 \\
\hline 17 & 13.28 & 0.22 & $\alpha$-Coumaric acid & 20.38 \\
\hline 18 & 13.52 & 0.61 & Benzoic acid & 573.71 \\
\hline 19 & 13.90 & 0.04 & 3,4,5- methoxy cinnamic acid & 3.19 \\
\hline 20 & 13.97 & 0.10 & Coumarin & 7.02 \\
\hline 21 & 14.35 & 0.15 & Salicylic acid & 56.31 \\
\hline 22 & 15.20 & 0.12 & Cinnamic acid & 3.89 \\
\hline & & $\begin{array}{l}\text { Total } \\
8.80 \%\end{array}$ & & \\
\hline
\end{tabular}

Egypt.J.Chem. 61, No.5 (2018) 
TABLE 3. The phenolic compounds identified in Aspergillus petrakii filtrate by reverse phase HPLC with diodearray detection.

\begin{tabular}{|c|c|c|c|c|}
\hline Peak No. & R.T. (min) & Area \% & Identified compound & $\mu \mathrm{g} / 100 \mathrm{ml}$ \\
\hline 1 & 7.23 & 0.57 & Gallic acid & 118.41 \\
\hline 2 & 7.34 & 0.13 & Pyrogallol & 1098.17 \\
\hline 3 & 7.92 & 0.19 & 4-Amino-benzoic acid & 14.62 \\
\hline 4 & 8.65 & 0.11 & Protocatechuic acid & 65.20 \\
\hline 5 & 8.69 & 0.07 & Catechin & 50.91 \\
\hline 6 & 9.21 & 0.10 & Chlorogenic acid & 31.91 \\
\hline 7 & 9.53 & 0.73 & Methyl gallate & 222.38 \\
\hline 8 & 9.72 & 0.17 & Epicatechin & 48.15 \\
\hline 9 & 10.26 & 0.01 & Caffeic acid & 1.77 \\
\hline 10 & 10.41 & 0.70 & Vanillic acid & 339.55 \\
\hline 11 & 11.70 & 0.12 & $p$-Coumaric acid & 17.84 \\
\hline 12 & 11.74 & 0.29 & Ferulic acid & 55.42 \\
\hline 13 & 12.15 & 0.06 & Iso-ferulic acid & 13.62 \\
\hline 14 & 12.68 & 0.14 & Reversetrol & 9.11 \\
\hline 15 & 12.98 & 0.13 & Ellagic acid & 455.32 \\
\hline 16 & 13.10 & 0.50 & $e$-vanillic acid & 2344.51 \\
\hline 17 & 13.31 & 0.11 & $\alpha$-Coumaric acid & 23.21 \\
\hline 18 & 13.43 & 0.28 & Benzoic acid & 607.15 \\
\hline 19 & 13.93 & 0.25 & 3,4,5- methoxy cinnamic acid & 40.90 \\
\hline 20 & 14.04 & 0.32 & Coumarin & 48.51 \\
\hline 21 & 14.32 & 0.17 & Salicylic acid & 147.31 \\
\hline \multirow[t]{2}{*}{22} & 15.20 & 0.22 & Cinnamic acid & 16.08 \\
\hline & & $\begin{array}{c}\text { Total } \\
5.37 \%\end{array}$ & & \\
\hline
\end{tabular}

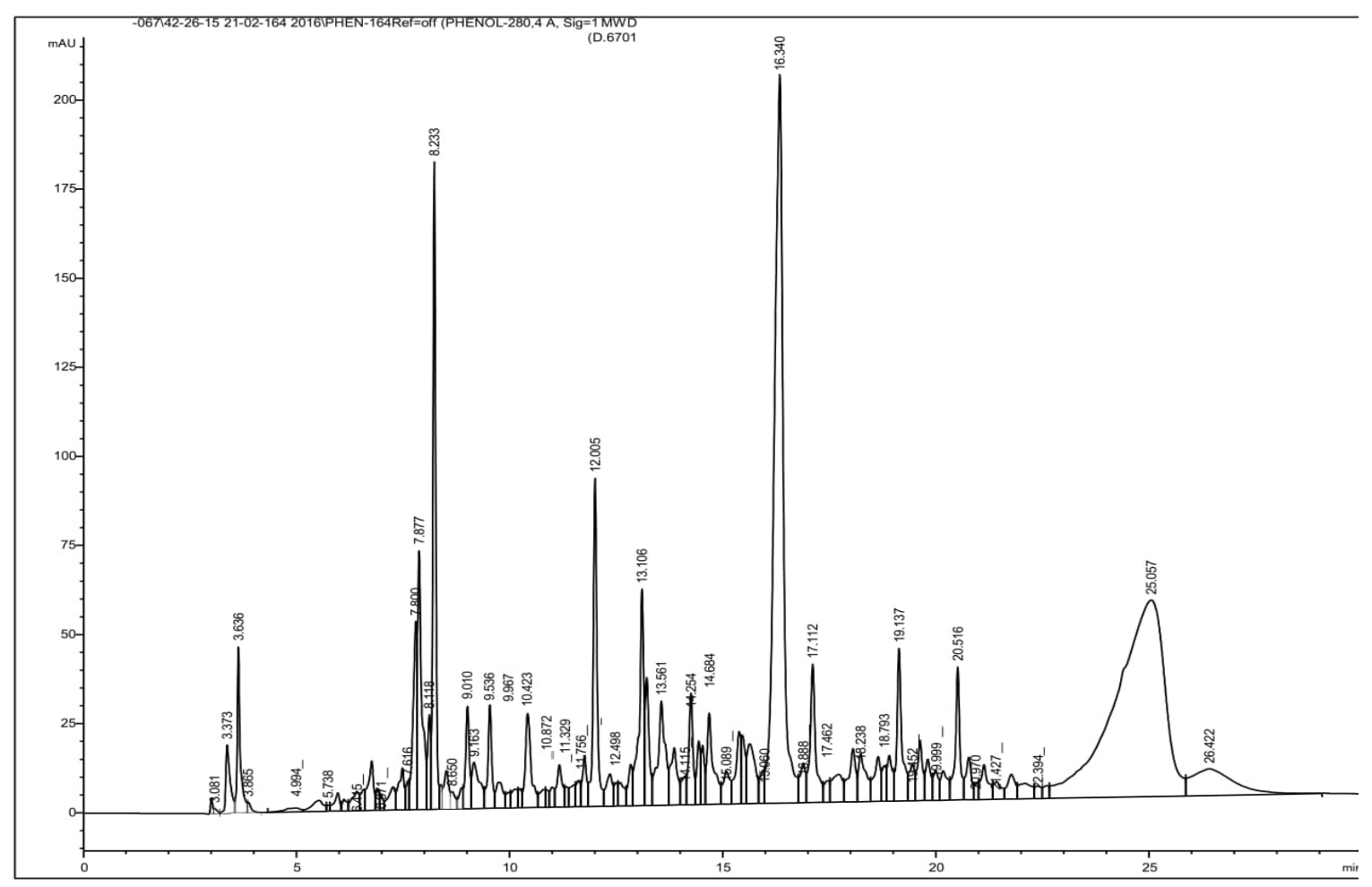

Fig. 1. HPLC chromatogram of Penicillium implicatum filtrate extract. 


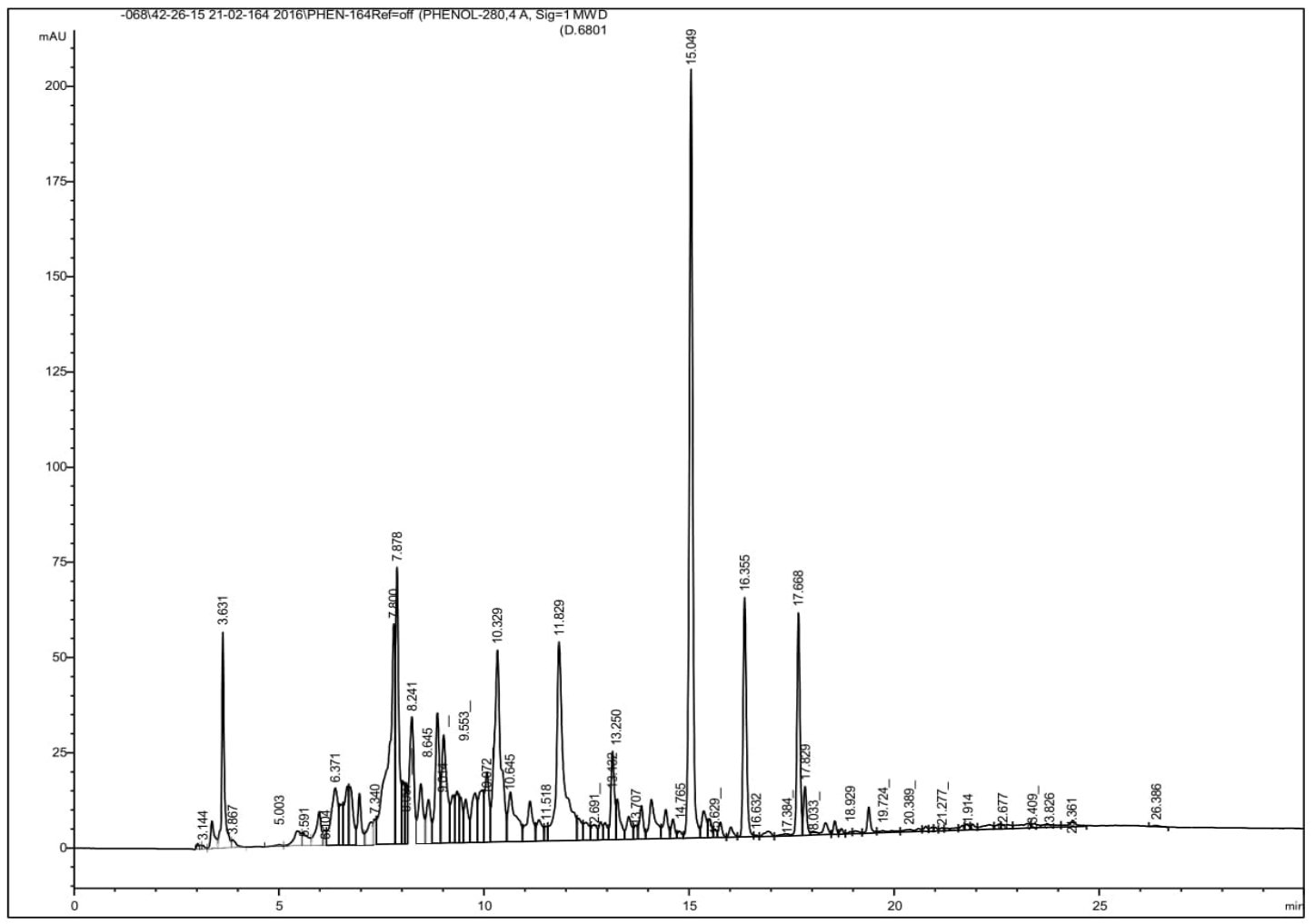

Fig. 2. HPLC chromatogram of Aspergillus niveus filtrate extract.

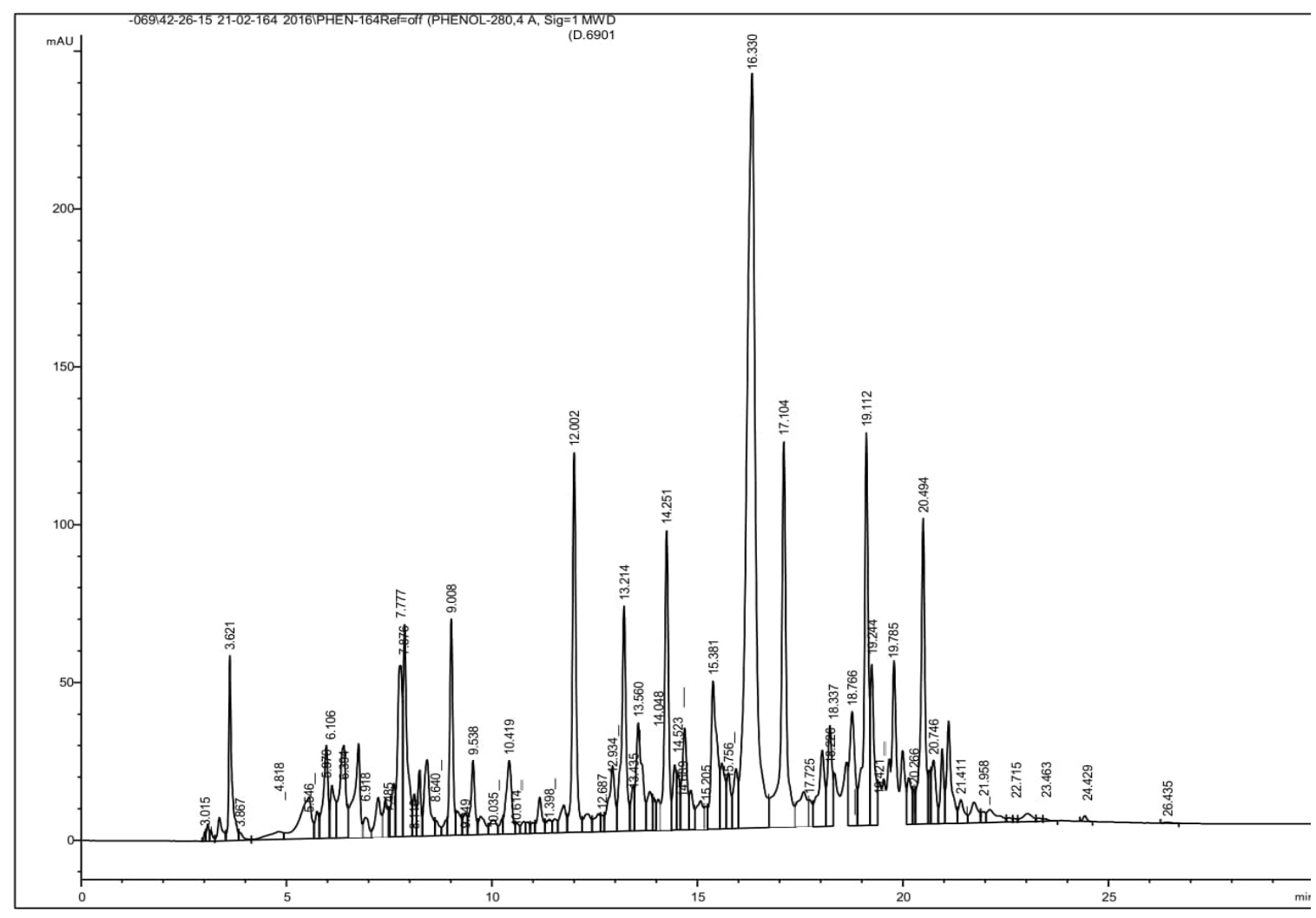

Fig. 3. HPLC chromatogram of Aspergillus petrakii filtrate extract.

Egypt.J.Chem. 61, No.5 (2018) 
TABLE 4. Inhibition zones diameters $(\mathrm{mm})$ of microorganisms exposed to methyl gallate, $p$-coumaric acid $(10 \%$ $\mathrm{v} / \mathrm{v})$ and reference antibiotics.

\begin{tabular}{|c|c|c|c|}
\hline Tested microorganisms & Methyl gallate & $p$-coumaric acid & Positive reference standard \\
\hline Gram Negative bacteria & & & Polymyxin \\
\hline \multirow[t]{2}{*}{ Pseudomonas aeruginosa (ATCC9027) } & $9 \pm 0.5$ & NI & $10 \pm 0.0$ \\
\hline & & & Ampicillin \\
\hline Escherichia coli (ATCC 35218) & $13 \pm 0.0$ & NI & $15 \pm 0.0$ \\
\hline \multicolumn{4}{|l|}{ Gram Positive bacteria } \\
\hline & & & Kanamycin \\
\hline Bacillus cereus (ATCC33018) & NI & $9 \pm 0.6$ & $12 \pm 0.0$ \\
\hline $\begin{array}{l}\text { Staphylococcus aureus sub sp. aureus } \\
\text { (MRSA) (ATCC43300) }\end{array}$ & $8 \pm 0.7$ & NI & $10 \pm 0.0$ \\
\hline Fungi & & & Nystatin \\
\hline Aspergillus niger (nrrl 326) & NI & NI & $15 \pm 0.0$ \\
\hline Candida albicans (ATCC 10231) & NI & NI & $13 \pm 0.0$ \\
\hline
\end{tabular}

NI: No inhibition
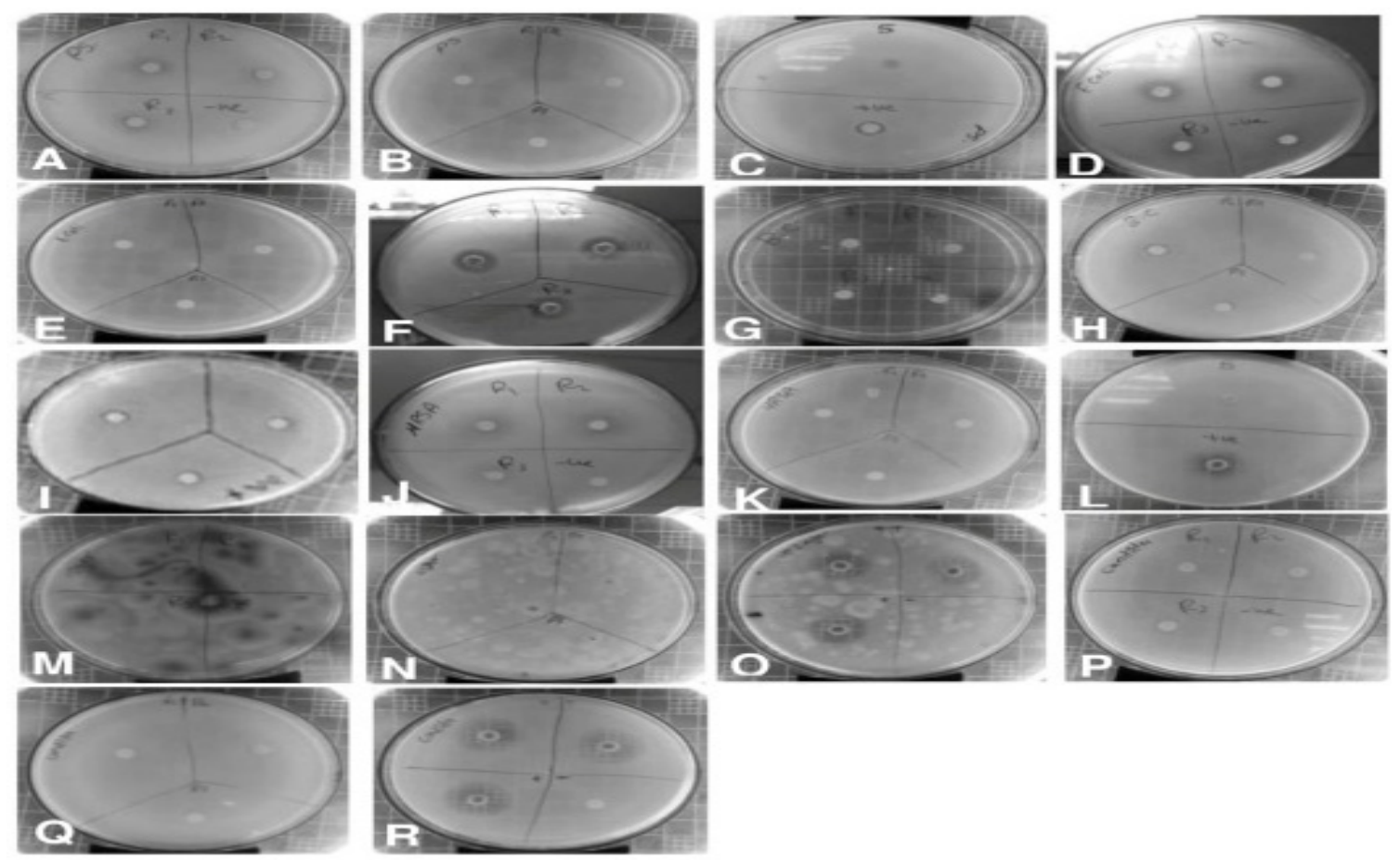

Fig. 4. Photos of media inoculated with tested microorganisms and exposed to discs saturated with methyl gallate, p-coumaric acid and reference antibiotics; A: $P$. aeruginosa + methyl gallate, B: $P$. aeruginosa + p-coumaric acid, C: Polymyxin, D: E. coli + methyl gallate, E: E. coli + p-coumaric acid , F: Ampicillin, G: B. cereus + methyl gallate, H: B. cereus ${ }^{+}$p-coumaric, I: Kanamycin, J: S. aureus sub sp. aureus (MRSA)+ methyl gallate, K: (MRSA)+ p-coumaric acid, L: Kanamycin, M: A.niger+ methyl gallate, N: $A$. niger+ p-coumaric acid, O:Nystatin, P: $C$. albicans + methyl gallate, Q: $C$. albicans ${ }^{+}$p-coumaric acid, R: Nystatin. R1, R2 and $\mathrm{R} 3$ represent three replicates, -ve represents DMSO as negative control, +ve represents reference antibiotic as positive control. 
Generally, phenolic acids are divided into two groups as hydroxybenzoic acid and hydroxycinnamic acid derivatives, $p$-coumaric acid belongs to the second category [36,37]. It is indicated that $p$-coumaric acid, which is stated to have biological activities and many physiological functions, is one of the most important phenolic acids [38-40]. $p$-coumaric acid (4-hydroxycinnamic acid), classified as a neutraceutical and phytochemical, is identified at significant levels in many fruits and vegetables as well as cereals.

To the best of our knowledge, this is the first time to identify this compound in fungal metabolites, the present work indicated that $p$-coumaric acid was only effective against Bacillus cereus with inhibition zone of $9 \mathrm{~mm}$ as compared to $12 \mathrm{~mm}$ for Kanamycin (Table 4 and Fig. 4 ). Our results coincide with Acar et $a l$., they declared that $p$-coumaric acid extracted from Crocus baytopiorum has a considerable antimicrobial effect against Bacillus cereus [41]. It is stated that $p$-coumaric acid exerts its effect through altering permeability of the cell membrane and disturbing cell functions [42]. Concerning the lack of antimicrobial activity of $p$-coumaric acid against certain bacteria in the current study, Krishna et al. noticed similar results especially at low concentrations, as the compound did not inhibit any of Klebsiella pneumonia, Escherichia coli, Staphylococcus aureus, Pseudomonas aeruginosa, Proteus vulgaris and Bacillus subtilis [43].

On the other hand, the results of the present study disagree with the findings of Sathish et al., they reported that $p$-coumaric acid showed high effect against Staphylococcus aureus and Escherichia coli and moderate effect on Streptococcus pyogenes and Klebsiella pneumonia while it had no effect on Salmonella typhi [44]. The observed different response of the same bacterial species to $p$-coumaric acid may be attributed to the difference in strains.

Regarding larvicidal activity, methyl gallate and $p$-coumaric acid were highly effective on miracidia as all the tested concentrations resulted in death of exposed miracidia after $15 \mathrm{~min}$. For cercariae exposed to the three concentrations of methyl gallate, no mortality was observed after $15 \mathrm{~min}$. As the time extended, the effect of these concentrations became more pronounced as $100 \%$ mortality was recorded after $45 \mathrm{~min}$ of cercarial exposure to 25 and $100 \mathrm{mg} / \mathrm{ml}$, while $60 \mathrm{~min}$ were required to attain this percentage in case of $50 \mathrm{mg} /$ $\mathrm{ml}$ (Fig. 5). Few studies demonstrated the adverse effect of methyl gallate on schistosomiasis worms and snails. Methyl gallate was previously isolated from the roots of Elephantorrhiza goetzei plant by Moyo et al. [45]. In Malawi and Zimbabwe, the root decoction of this plant is taken orally for the treatment of Bilharzia [46, 47]. Moreover, water extract of the plant roots showed lethal concentration of $0.5 \mathrm{mg} / \mathrm{ml}$ against Schistosoma mansoni. E. goetzei stem bark extract was also effective against schistosomules as its lethal concentration was $0.8 \mathrm{mg} / \mathrm{ml}$ [48]. Recently, methyl gallate was found to be responsible for the molluscicidal effect of Penicillium janthinellum against schistomiasis snails [16].

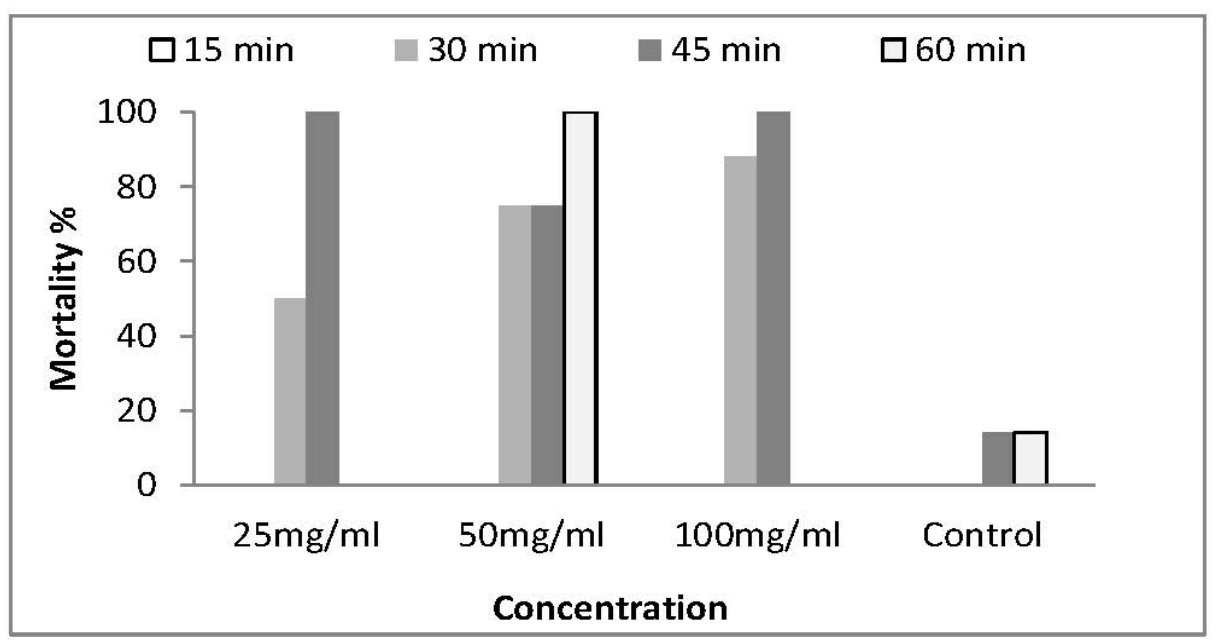

Fig. 5. Effect of methyl gallate on mortality percentage of $S$. mansoni cercariae at certain time intervals. Egypt.J.Chem. 61, No.5 (2018) 
For cercariae exposed to $25 \mathrm{mg} / \mathrm{ml}$ $p$-coumaric acid in the current study, $40 \%$ mortality was observed after $15 \mathrm{~min}$, as the time extended to $30 \mathrm{~min}$, mortality percentage increased to $90 \%$. All cercariae exposed to that concentration died after $45 \mathrm{~min}$, while in case of cercariae treated with the two higher concentrations, $100 \%$ mortality was attained just after $15 \mathrm{~min}$ (Fig. 6). It was found that the extracts from plants belonging to family Lamineceae, which were effective against infectious diseases, contain $p$-coumaric acid among their constituents [49]. Moreover, Alvarenga et al. demonstrated that the ethyl acetate fraction of Cuspidaria pulchra plant which killed the adult schistosomes in vitro was shown to contain $p$-coumaric acid as one of the five major compounds identified [50].

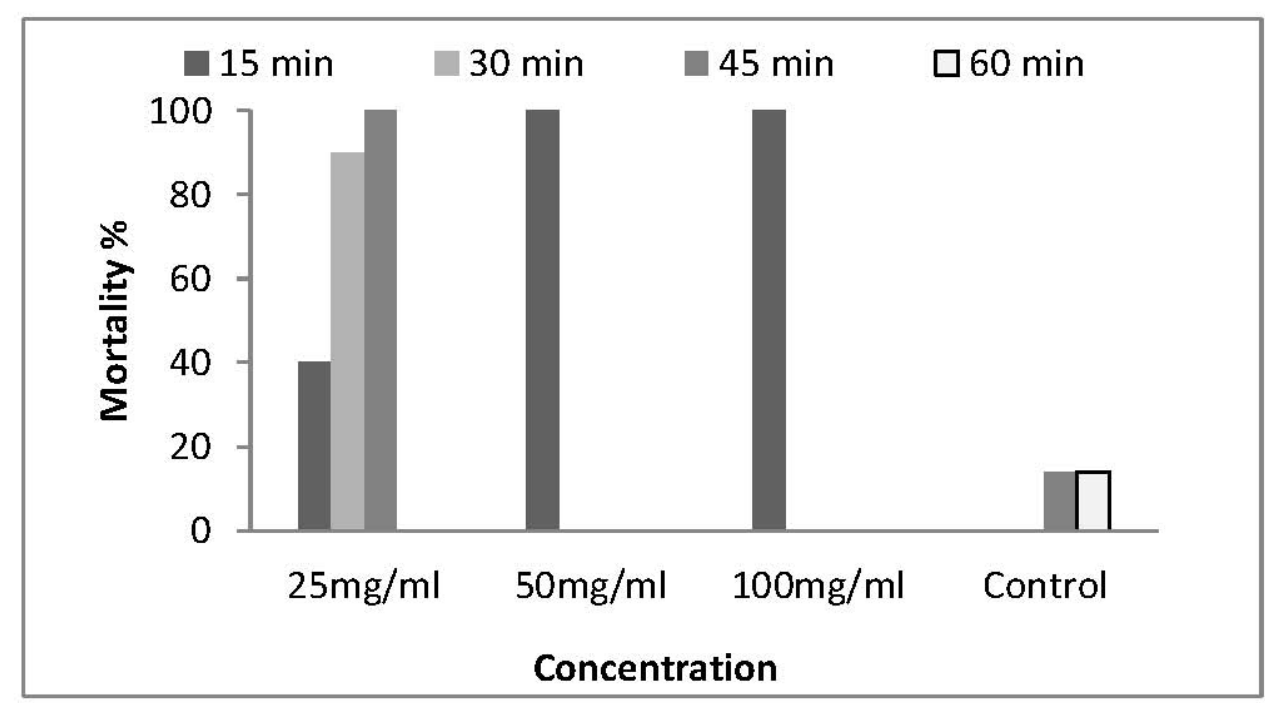

Fig. 6. Effect of $p$-coumaric acid on mortality percentage of $S$. mansoni cercariae at certain time intervals.

\section{Conclusion}

Penicillium implicatum, Aspergillus niveus and Aspergillus petrakii are three promising freshwater-derived fungi as they produce a number of phenolic compounds, amongst them methyl gallate and $p$-coumaric acid. These two compounds were shown to have antibacterial effect, and miracicidal and cercaricidal activities.

\section{References}

1. Hamed A.A., Abdel-Aziz M.S., Fadel M. and Ghali M.F., Antidermatophytes from bioactive secondary metabolites of local Streptomyces spp. Journal of Innovations in Pharmaceutical and Biological Sciences, 3, 155-165 (2016).

2. Gloer J.B. The chemistry of fungal antagonism and defence. Canadian Journal of Botany, 73,12651274 (1995).

3. Gloer J.B., TOR: “Environmental and Microbial
Relationships". In Wicklow D.T., Soderstorm B.E. (Ed). TOR-mycota. Heidelberg, Springer Verlag, 249-268 (1997).

4. Grabley S., Thiericke R., Zeeck A. "The Chemical Screening Approach". Drug Discovery from Nature, 124-148 (1999).

5. Shen K.Z., Gao S., Gao Y.X., Wang A.R., Xu Y.B., Sun R., Hu P.G., Yang G.F., Li A.J., Zhong D., Liu H.Y. and Dong J.Y., Novel dibenzo [b, e] oxepinones from the freshwater-derived fungus Chaetomium sp. YMF 1.02105. Planta Medica, 78, 1837-1843 (2012).

6. Xu X., De Guzman F.S., Gloer J.B. and Shearer C.A., Stachybotrins A and B: novel bioactive metabolites from a brackish water isolate of the fungus Stachybotrys sp. Journal of Organic Chemistry, 57, 6700-6703 (1992).

7. Poch G.K., Gloer J.B., and Shearer C.A., New 
bioactive metabolites from a freshwater isolate of the fungus Kirschsteiniothelia sp. Journal of Natural Products, 55, 1093-1099 (1992).

8. Oh H., Kwon T.O., Gloer J.B., Marvanová L. and Shearer C.A., Tenellic Acids A- D: new bioactive diphenyl ether derivatives from the aquatic fungus Dendrospora tenella. Journal of Natural Products, 62, 580-583 (1999).

9. Oh H., Swenson D.C., Gloer J.B. and Shearer C.A., New bioactive rosigenin analogues and aromatic polyketide metabolites from the freshwater aquatic fungus Massarina tunicata. Journal of Natural Products, 66, 73-79 (2003).

10. Li C., Nitka M.V., Gloer J.B., Campbell J. and Shearer C.A., Annularins A- H: New polyketide metabolites from the freshwater aquatic fungus Annulatascus triseptatus. Journal of Natural Products, 66, 1302-1306 (2003).

11. Reátegui R.F., Gloer J.B., Campbell J. and Shearer C.A. Ophiocerins A- D and ophioceric acid: tetrahydropyran derivatives and an africane sesquiterpenoid from the freshwater aquatic fungus Ophioceras venezuelense. Journal of Natural Products, 68, 701-705 (2005).

12. Jiao P., Swenson D.C., Gloer J.B., Campbell J. and Shearer C.A., Decaspirones A- E, bioactive spirodioxynaphthalenes from the freshwater aquatic fungus Decaisnella thyridioides. Journal of Natural Products, 69, 1667-1671 (2006).

13. Mudur S.V., Swenson D.C., Gloer J.B., Campbell J. and Shearer C.A., Heliconols A- C: Antimicrobial hemiketals from the freshwater aquatic fungus Helicodendron giganteum. Organic Letters, 8 , 3191-3194 (2006).

14. Shaaban M., Nasr H., Hassan A.Z. and Asker M.S., Bioactive secondary metabolities from endophytic Aspergillus fumigatus: structural elucidation and bioactivity studies. Revista latinoamericana de química , 41, 50-60(2013).

15. Proestos C., Chorianopoulos N., Nychas G.J. and Komaitis M., RP-HPLC analysis of the phenolic compounds of plant extracts. Investigation of their antioxidant capacity and antimicrobial activity. Journal of Agricultural and Food Chemistry, 53, 1190-1195 (2005).
16. Saad A.A., Khalil M.T., Ragab F.M Mekawey A.A. and Abdel-Wareth M.T.A., Separation of a compound effective against Biomphalaria alexandrina snails from the filtrate of Penicillium janthinellum. International Journal of Environmental Studies, 73, 1-17(2016).

17. Raper K.B., Fennell D.I., “The Genus Aspergillus”, The Williams and Wilkins Co, Baltimore, p. 686 (1965).

18. de Hoog G.S., Guarro J., Gene J and Figueras M.J., "Atlas of Clinical Fungi". Centraalbureau voor Schimmelcultures, Utrecht, The Netherlands and Universitat Rovira i Virgili. Reus, Spain (2000).

19. Hall I.M. and Bell J.V., Further studies on the effect of temperature on the growth of some entomophthoraceous fungi. Journal of Insect Pathology, 3, 289(1961).

20. Goupy P., Hugues M., Boivin P. and Amiot M.J., Antioxidant composition and activity of barley (Hordeum vulgare) and malt extracts and of isolated phenolic compounds. Journal of the Science of Food and Agriculture, 79, 1625-1634 (1999).

21. Bettelheim F., Landesberg J. and Saunders W.B., "Column and paper chromatography: separation of plant pigments. In Laboratory Experiments for General Organic \& Biochemistry, Ed. Saunders, Harcourt Brace Co., Florida, 32887, America, 265 271(1995)

22. Evans, W. C., Deterioration of stored Drugs. Trease and Evans Pharmacognosy. pp. 119-130 (1996).

23. Bauer A.W., Kirby W.M., Sherris J.C. and Turck M. Antibiotic susceptibility testing by a standardized single disk method. American Journal of Clinical Pathology, 45, 493-496 (1966).

24. Lahlou M., Potential of Origanum compactum as a cercaricide in Morocco. Annals of Tropical Medicine and Parasitology, 96, 587-593 (2002).

25. Devi P., Rodrigues C., Naik C.G. and D'souza L., Isolation and characterization of antibacterial compound from a mangrove-endophytic fungus, Penicillium chrysogenum MTCC 5108. Indian Journal of Microbiology, 52, 617-623(2012).

26. Kaur H., Onsare J.G., Sharma V. and Arora D.S., Isolation, purification and characterization of novel antimicrobial compound 7-methoxy-2, 2-dimethyl4-octa-4', 6'-dienyl-2 H-napthalene-1-one from Penicillium sp. and its cytotoxicity studies. $A M B$ Express, 5, 40 (2015). 
27. Marinho A.M., Marinho P.S., Santos L.S., Rodrigues Filho E. and Ferreira I.C., Active polyketides isolated from Penicillium herquei. Anais da Academia Brasileira de Ciências, 85, 909-912 (2013).

28. Li X.J., Zhang Q., Zhang A.L. and Gao J.M., Metabolites from Aspergillus fumigatus, an endophytic fungus associated with Melia azedarach, and their antifungal, antifeedant, and toxic activities. Journal of Agricultural and Food Chemistry, 60, 3424-3431 (2012).

29. Liu D., Huang Y., Li C., Ma L., Pan X., Ferreira D. and Liu W., A new sesquiterpenoid derivative from the coastal saline soil fungus Aspergillus fumigatus. Records of Natural Products, 10, 708713 (2016).

30. Ekaprasada M.T., Nurdin H., Ibrahim S. and Dachriyanus D., Antibacterial Activity of methyl gallate isolated from the leaves of Toona sureni. International Journal on Advanced Science, Engineering and Information Technology, 5, 280282 (2015).

31. Chaudhuri D., Ghate N.B., Singh S.S. and Mandal N., Methyl gallate isolated from Spondias pinnata exhibits anticancer activity against human glioblastoma by induction of apoptosis and sustained extracellular signal-regulated kinase 1/2 activation. Pharmacognosy Magazine, 11, 269-277 (2015).

32. Ekaprasada M.T., Nurdin H., Ibrahim S. and Dachriyanus D., Antioxidant activity of methyl gallate isolated from the leaves of Toona sureni. Indonesian Journal of Chemistry, 9, 457460 (2010).

33. Kamatham S., Kumar N. and Gudipalli P., Isolation and characterization of gallic acid and methyl gallate from the seed coats of Givotia rottleriformis Griff. and their anti-proliferative effect on human epidermoid carcinoma A431 cells. Toxicology Reports, 2, 520-529 (2015).

34. Choi J.G., Kang O.H., Lee Y.S., Oh Y.C., Chae H.S., Jang H.J., Shin D.W. and Kwon D.Y., Antibacterial activity of methyl gallate isolated from Galla rhois or carvacrol combined with nalidixic acid against nalidixic acid resistant bacteria. Moecules, 14, 1773-1780 (2009).

35. Mason T.L. and Wasserman B.P., Inactivation of red beet beta-glucan synthase by native and oxidized phenolic compounds. Phytochemistry, 26, 2197-2202 (1987).
36. Karamac M., Bucinski A., Pegg R.B. and Amarowicz R. Antioxidant and antiradical activity of ferulates. Czech Journal of Food Science, 23, 64-68 (2005).

37. Mattila P., Pihlava J.M. and Hellstr€om J., Contents of phenolic acids, alkyl- and alkenylresorcinols, and avenanthramides in commercial grain products. Journal of Agricultural and Food Chemistry, 53, 8290-8295 (2005).

38. Kadoma Y. and Fujisawa S., A comparative study of the radical- scavenging activity of the phenolcarboxylic acids caffeic acid, p-coumaric acid, chlorogenic acid and ferulic acid, with or without 2-mercaptoethanol, a thiol, using the induction period method. Molecules, 13, 2488 2499 (2008).

39. Ota A., Abramovi H., Abram V. and Ulrih N.P., Interactions of p-coumaric, caffeic and ferulic acids and their styrenes with model lipid membranes. Food Chemistry, 125, 1256 -1261(2011).

40. Kumar N., Pruthi V. and Goel N., Structural, thermal and quantum chemical studies of p-coumaric and caffeic acids. Journal of Molecular Structure, 1085, 242-248 (2015).

41. Acar G., Dogan N., Duru M. and Kivrak I., Phenolic profiles, antimicrobial and antioxidant activity of the various extracts of Crocus species in Anatolia. African Journal of Microbiology Research, 4, 1154-1161 (2010).

42. Lou Z., Wang H., Rao S., Sun J., Ma C. and Li J., p-coumaric acid kills bacteria through dual damage mechanisms. Food Control, 25, 550-554 (2012).

43. Krishna N.A.V., Nadeem M.D., Saradhi M.P., Mahendran B. and Bharathi S., Cumulative activity of the $p$-coumaric acid and syringaldehyde for antimicrobial activity of different microbial strains. European Journal of Experimental Biology, 4, 40-43(2014).

44. Sathish M., Meenakshi G., Xavier S. and Sebastian S., Conformational stability, TGA, and molecular docking investigations of $p$-coumaric acid with special relevance to anti-cancer and antibacterial activity. Acta Physica Polonica, A, 131(6) (2017). 
45. cF., Gashe B.A. and Majinda R.R.T., A new flavan from Elephantorrhiza goetzei. Fitoterapia, 70, 412416 (1999).

46. Msonthi J.D., In Proceedings of a National Forestry Research Symposium: Herbs of medicinal value in Malawi: a potential for drug formulation pp. 146-161 (1987).

47. Ndamba J., Nyazema N., Makaza N., Anderson C. and Kaondera K.C., Traditional herbal remedies for the treatment of urinary schistosomiasis in Zimbabwe. Journal of Ethnopharmacololgy, 42, 125-132 (1994).

48. Mølgaard P., Nielsen S.B., Rasmussen D.E., Drummond R.B., Makaza N. and Andreassen J., Anthelmintic screening of Zimbabwean plants traditionally used against schistosomiasis. Journal of Ethnopharmacololgy, 74, 257-264 (2001).

49.Ozkan G., Kamiloglu S., Ozdal T., Boyacioglu D. and Capanoglu E., Potential use of Turkish medicinal plants in the treatment of various diseases. Molecules, 21, 257 (2016).

50. Alvarenga T.A., Bêdo T.R., Braguine C.G., Gonçalves U.O., Magalhães L.G., Rodrigues V.,Gimenez V.M., Groppo M., Silva M.L.A., Cunha W.R. and Januário A.H., Evaluation of Cuspidaria pulchra and its isolated compounds against Schistosoma Mansoni adult worms. International Journal of Biotechnology for Wellness Industries, 1, 121-127 (2012).

(Received 19/3/2018; accepted 21/6/2018)

\section{التنقيب الحيوى عن المركبات الفينولية فى بعض فطريات المياه العذبة مع التركيز على التئ

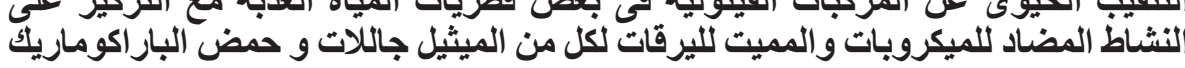

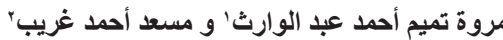

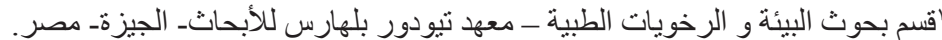

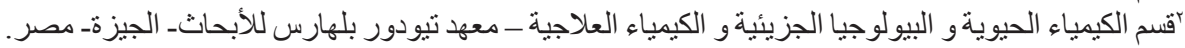

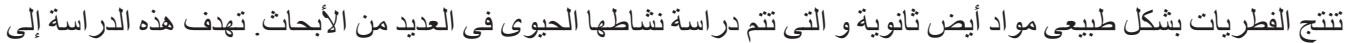

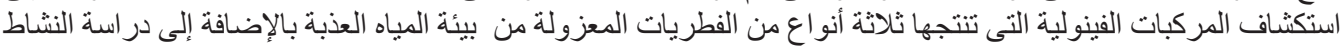

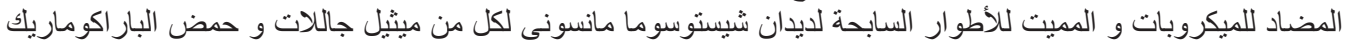

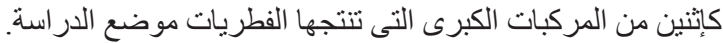

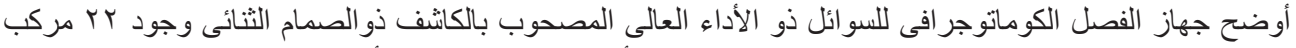

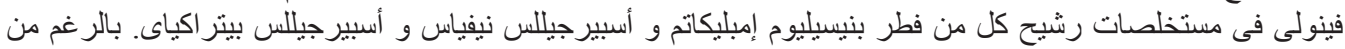

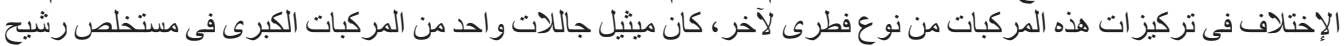

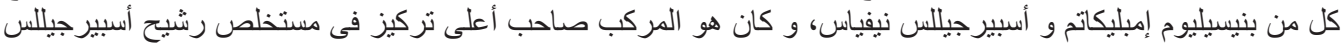

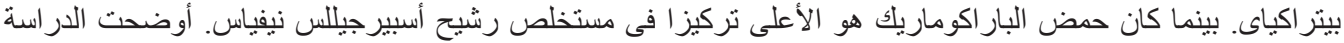

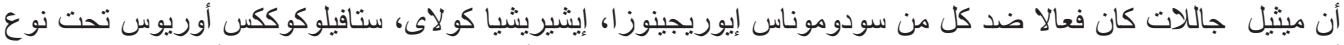

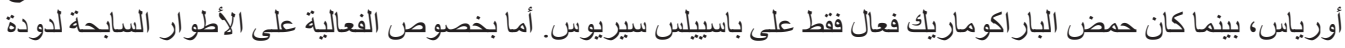

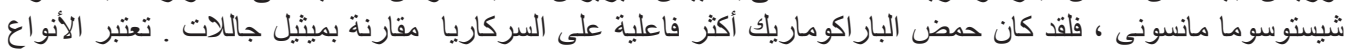

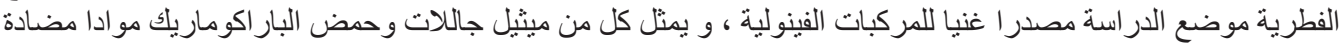
للبكتريا و مميتة للأطو ار اليرقية لديدان الثيستوسومان. 